\title{
Stress Degradation Assessment of Lamotrigine Using a Validated Stability-Indicating HPTLC Method
}

\author{
Karim Michail, ${ }^{1,2}$ Hoda M. Daabees, ${ }^{1}$ Youssef Beltagy, \\ Magdi Abdel-Khalek, ${ }^{1}$ and Mona M. Khamis ${ }^{1}$ \\ ${ }^{1}$ Department of Pharmaceutical Chemistry, Faculty of Pharmacy, University of Alexandria, Khartoum Square 1, \\ Azarita, Alexandria 21521, Egypt \\ ${ }^{2}$ Dentistry/Pharmacy Centre, Faculty of Pharmacy and Pharmaceutical Sciences, University of Alberta, \\ Edmonton AB, Canada T6G 2N8
}

Correspondence should be addressed to Karim Michail; michail@ualberta.ca

Received 4 July 2012; Revised 24 August 2012; Accepted 26 August 2012

Academic Editor: Victor David

Copyright (C) 2013 Karim Michail et al. This is an open access article distributed under the Creative Commons Attribution License, which permits unrestricted use, distribution, and reproduction in any medium, provided the original work is properly cited.

\begin{abstract}
In this work, a sensitive and stability-indicating HPTLC method for the determination of lamotrigine is presented. According to the International Conference on Harmonization guidelines Q1A, lamotrigine was exposed to a variety of stress conditions; these include heating in acidic, basic and neutral media. Its stability towards oxidative stress, humidity, high temperature and direct sunlight was also examined. Separation of the drug from its forced degradation impurities was achieved using TLC silica gel plates and a mobile phase composed of ethyl acetate: methanol: ammonia. The linear regression analysis of the data obtained for the correlation plots showed good linearity over the concentration range of 10-300 ng/spot. The forced degradation studies showed that lamotrigine is susceptible to degradation under acidic, basic, neutral and oxidative conditions, among which alkaline-induced hydrolysis had the highest degradative potential. Alternatively, the drug was stable under heat, humidity, and daylight stress factors. In order to assess the purity and stability of the drug in tablet formulations, the developed method was applied to the analysis of commercial tablets in brand and generic products. The obtained results showed that the degradation of the drug has not occurred in the marketed formulations that were analyzed by the described methodology.
\end{abstract}

\section{Introduction}

Lamotrigine (LAM) [6-(2,3-dichlorophenyl)-1,2,4-triazine3,5 -diamine] is an antiepileptic drug approved as a monotherapy for partial seizures and for the adjunctive treatment of partial seizures, primary and secondary generalized tonic-clonic seizures, and in patients with Lennox-Gastaut syndrome. It is also approved for use in the maintenance treatment of bipolar disorder to delay the time to occurrence of mood episodes [1-3].

The USP describes an HPLC assay with UV detection for the assay of LAM in pure and tablet form [4]. On the other hand, the BP describes a nonaqueous acid-base titration for the assay of the pure drug [5]. Moreover, techniques as HPLC $[6,7]$ and TLC [7] were used to quantify LAM in the presence of its related impurities. The drug was also determined in tablet form using a TLC method [8]. The Literature also contains a spectrophotometric direct UV method [9] as well as a spectrofluorimetric one utilizing the reaction with ophthalaldehyde [10] for its determination in tablet form. Pertaining to stability-indicating studies, 2 HPLC methods for the separation of the investigated drug from its forceddegradation products were recently reported $[9,11]$. To the best of our knowledge, HPTLC has not been previously reported for the stress testing of LAM and its determination in the presence of its forced degradation products. It is noteworthy that HPTLC has become an essential tool of modern analytical chemistry to assess the stability of a wide range of pharmaceuticals under a variety of stress conditions [12-14]. From another perspective, the International Conference on Harmonisation (ICH) guidelines Q1A [15] emphasize on the stability testing of new drug substances and products. This 
testing aims at examining the features which are vulnerable to change under the influence of different environmental conditions during storage such as temperature, humidity, and light and thus impacting the quality, safety, and/or efficacy of the drug substance. In these guidelines, it is mentioned that forced decomposition studies should be carried out at temperatures rising in $10^{\circ} \mathrm{C}$ increments, humidity (e.g., $75 \%$ $\mathrm{RH}$ or greater), and under oxidative and photolytic conditions. In addition, the susceptibility of the drug substance to hydrolysis across a wide range of $\mathrm{pH}$ values when in solution or suspension should be evaluated. Therefore, this work was directed towards the development of a simple and sensitive stability-indicating HPTLC that can be used to establish a stability profile of the drug and consequently assess its purity in bulk and tablet form.

\section{Experimental}

2.1. Materials. All reagents and solvents used were of analytical grade. LAM was kindly supplied as a gift sample by Delta Pharm (Cairo, Egypt). $1 \mathrm{mg} / \mathrm{mL}$ standard stock solution was prepared in methanol and was further diluted by the same solvent to produce 0.1 and $0.5 \mathrm{mg} / \mathrm{mL}$ standard working solutions.

2.2. HPTLC Instrumentation. The samples were spotted in the form of bands of $5 \mathrm{~mm}$ width with a Camag microlitre syringe under nitrogen stream using a Camag Linomat IV sample applicator (Switzerland). Precoated TLC silica gel aluminum plates $60 \mathrm{~F}_{254}(20 \times 10 \mathrm{~cm}, 200 \mu \mathrm{m}$ thickness $)$ purchased from Fluka (Buchs, Switzerland) were used. A constant application rate of $0.15 \mu \mathrm{L} / \mathrm{s}$ was employed with the distance between 2 bands adjusted at $4 \mathrm{~mm}$. The slit dimensions were kept at $4 \times 0.45 \mathrm{~mm}$, and a scanning speed of $20 \mathrm{~mm} / \mathrm{s}$ was utilized. The mobile phase consisted of ethyl acetate-methanol-ammonia $(17: 2: 1, \mathrm{v} / \mathrm{v} / \mathrm{v})$, and $15 \mathrm{~mL}$ of which was used per chromatographic run. Linear ascending development was performed in a Camag twin trough glass chamber $(20 \times 20 \mathrm{~cm})$ presaturated with the mobile phase for $15 \mathrm{~min}$ at room temperature. The length of the chromatogram run was $89 \pm 2 \mathrm{~mm}$. Subsequent to the development, the plates were air dried and scanned densitometrically in the absorbance mode at $310 \mathrm{~nm}$ using Camag TLC scanner III operated by CATS software (V 3.15). The source of the radiation was the deuterium lamp.

2.3. Calibration Standards. Serial volumes of $0.1 \mathrm{mg} / \mathrm{mL}$ LAM standard working solution were transferred into a set of $10 \mathrm{~mL}$ volumetric flasks, and the volumes were completed to mark with methanol. Each calibration concentration was prepared in triplicates, and $5 \mu \mathrm{L}$ aliquots of each were spotted onto the TLC plate to obtain final concentrations of $10-300 \mathrm{ng} / \mathrm{spot}$. Plate spotting and development as well as spot scanning and quantitation were performed as mentioned in Section 2.2, and the calibration curve was constructed.
2.4. Assay of Tablets. Ten tablets were weighed, powdered and thoroughly mixed. An accurately weighed quantity of the powdered tablets equivalent to $50 \mathrm{mg}$ drug according to the label claim was sonicated for $2 \times 5$ min with $2 \times 20 \mathrm{~mL}$ methanol portions. The combined extracts were filtered into a $50 \mathrm{~mL}$ volumetric flask, and the volume was finally completed to the mark with methanol. Ten $\mathrm{mL}$ of this solution was diluted to $100 \mathrm{~mL}$ with methanol to produce a $0.1 \mathrm{mg} / \mathrm{mL}$ LAM solution. Aliquots of this solution were treated as in Section 2.3. The nominal contents of the tablets were then calculated using the developed regression equation.

2.5. Accelerated Degradation of LAM. The $0.5 \mathrm{mg} / \mathrm{mL}$ LAM standard working solution was used in the forced degradation studies to provide evidence of the stability-indicating capacity and the selectivity of the proposed method. With the exception of the photolytic degradation, all forced degradation studies were performed in the dark in order to exclude the possible degradative effect of light.

2.5.1. Acid and Base-Induced Degradation. To $10 \mathrm{~mL}$ of the standard working solution, $10 \mathrm{~mL}$ of $5 \mathrm{M} \mathrm{HCl}$ or $2.5 \mathrm{M} \mathrm{NaOH}$ was added separately. These mixtures were refluxed in a thermostatically controlled water bath maintained at $80^{\circ} \mathrm{C}$ for $2 \mathrm{~h}$. The samples were then cooled to room temperature and quantitatively transferred into $25 \mathrm{~mL}$ volumetric flasks. Finally, the volumes were completed to mark with methanol. One $\mu \mathrm{L}$ of each solution ( $200 \mathrm{ng} / \mathrm{spot}$ ) was applied on the plate, and the chromatograms were run as previously described.

2.5.2. Neutral Hydrolysis-Induced Degradation. Ten $\mathrm{mL}$ of the LAM standard working solution was refluxed with $10 \mathrm{~mL}$ water in a thermostatically controlled water bath maintained at $80^{\circ} \mathrm{C}$ for $72 \mathrm{~h}$. The solution was then treated as in the Section 2.5.1.

2.5.3. Hydrogen Peroxide-Induced Degradation. To $10 \mathrm{~mL}$ of the standard working solution, $10 \mathrm{~mL}$ of $\mathrm{H}_{2} \mathrm{O}_{2}(30 \% \mathrm{v} / \mathrm{v})$ and $20 \mathrm{~mL}$ water were added, and the mixture was refluxed in a thermostatically controlled water bath maintained at $80^{\circ} \mathrm{C}$ for $4 \mathrm{~h}$. The solution was then heated in a boiling water bath for 30 min to remove completely the excess of $\mathrm{H}_{2} \mathrm{O}_{2}$. Afterwards, the solution was cooled and quantitatively transferred to a $50 \mathrm{~mL}$ volumetric flask and then completed to volume with methanol. Finally, $2 \mu \mathrm{L}$ solution ( $200 \mathrm{ng} / \mathrm{spot}$ ) was applied on the plate, and the chromatograms were run as previously described.

2.5.4. Dry Heat-Induced Degradation. Pure drug powder was spread as a thin layer on a Petri dish and stored in a hot air oven at $100^{\circ} \mathrm{C}$ for $72 \mathrm{~h}$. A methanolic solution was then prepared using the stressed powder at a concentration of $0.2 \mathrm{mg} / \mathrm{mL}$. One $\mu \mathrm{L}$ of this solution ( $200 \mathrm{ng} / \mathrm{spot}$ ) was applied on the plate, and the chromatograms were run as previously described. 
2.5.5. Humidity-Induced Degradation. Pure drug powder was spread as a thin layer on a Petri dish and stored in a humidity chamber (relative humidity $=75 \%$ ) maintained at $40^{\circ} \mathrm{C}$ for $72 \mathrm{~h}$. The procedure described in Section 2.5.4 was then followed.

2.5.6. Photolytic Degradation. Ten $\mathrm{mL}$ of the standard working solution was transferred into a $25 \mathrm{~mL}$ volumetric flask. The volume was completed to mark with methanol, and the solution was exposed to direct sunlight for $72 \mathrm{~h}$ (12 days, $9: 00-15: 00)$. Finally, $1 \mu \mathrm{L}$ of this solution $(200 \mathrm{ng} / \mathrm{spot})$ was applied on the plate, and the chromatograms were run as previously described.

\section{Results and Discussion}

3.1. Optimization of the Mobile Phase. In order to optimize the separation of intact drug from its degradation products, drug solutions were spotted and developed in different mobile phases. A system composed of $n$-hexanemethanol [16:4] was found to be of low polarity index (1.4); accordingly, none of the components ascended from baseline. On the other hand, the previous mixture at $[4: 16]$ was highly polar (polarity index: 5.3) causing the intact drug and its degradation products to coelute with the solvent front. The previous mixture was also tried at a ratio of $[10: 10]$; however, this failed to resolve the drug from its degradation products. Acetone toluene $[16: 4]$ resulted in poor resolution as well. Ethyl acetate-methanol in ratios $[17: 2,15: 4,11: 8]$ resulted in satisfactory separation. Consequently, the ratio showing the most adequate retention factor $\left(R_{f}\right.$ value) $[17: 2]$ was chosen. The addition of ammonia was found to enhance peak shape and symmetry leading to compact spots. Therefore, the optimized mobile phase consisted of ethyl acetate: methanol:ammonia $[17: 2: 1]$, and LAM was observed at an $R_{f}$ value of $0.59 \pm 0.1$. The chamber was saturated with the mobile phase at room temperature for $15 \mathrm{~min}$ prior to development. The optimized procedure resulted in well-defined spots with reproducible $R_{f}$ values (Figure 1).

\subsection{Method Validation}

3.2.1. Linearity. Six concentrations of the drug over a concentration range of $2-60 \mathrm{ng} / \mu \mathrm{L}$ corresponding to $10-300 \mathrm{ng} / \mathrm{spot}$ were prepared in triplicates and calibration curve for LAM was constructed by plotting the average peak area of the drug as a function of the corresponding concentration. The regression equation was obtained using the least squares regression model. The good linearity of the proposed method was validated by an acceptable correlation coefficient and an insignificant difference from zero for the intercept $[16,17]$ (Table 1).

3.2.2. Accuracy and Precision. The accuracy and the intraand interday reproducibilities for the determination of the drug among its degradation products were tested using 5 replicates at 3 different concentration levels, namely 30 ,

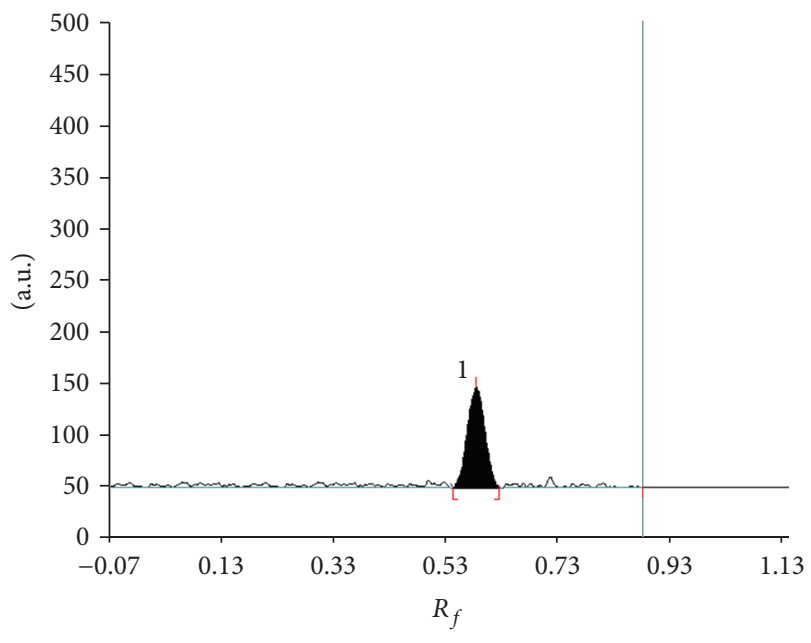

FIgURE 1: A typical HPTLC chromatogram of LAM scanned at $310 \mathrm{~nm}\left(100 \mathrm{ng} / \mathrm{spot}, R_{f}=0.59\right)$.

TABLE 1: Regression and statistical parameters for the determination of LAM using the proposed HPTLC method.

\begin{tabular}{lc}
\hline Parameter & Value \\
\hline Linearity range (ng/spot) & $10-300$ \\
$r$ & 0.9998 \\
$a$ & 26.75 \\
$b$ & 126.31 \\
$S_{a}$ & 32.77 \\
$S_{b}$ & 1.08 \\
$S_{y / x}$ & 56.27 \\
$t^{*}$ & 0.82 \\
\hline${ }^{*}$ Statistical significance of the intercept $t=|a| / S_{a}[16,17]$ theoretical value \\
of $t=2.78$ (at $P=0.05$ level of significance, number of points $=6$ ).
\end{tabular}

150 , and $250 \mathrm{ng} / \mathrm{spot}$ over 3 consecutive days. The proposed method is deemed accurate as warranted by the low values of percentage relative error $(\mathrm{Er} \%)$ gathered in Table 2. The percentage relative standard deviation (RSD\%) values did not exceed $0.91 \%$ indicating acceptable intraand interday precisions for the determination of LAM in presence of its degradants by the proposed method (Table 2).

3.2.3. Limits of Detection (LOD) and Quantification (LOQ). For the estimation of LOD and LOQ, blank methanol was spotted 6 times following the same parameters described for the construction of the calibration curve, and the noise detected at the same $R_{f}$ value of LAM was computed. The signal-to-noise ratio $3: 1$ [18] was considered as the LOD and was found to be $2.34 \mathrm{ng} / \mathrm{spot}$. LOQ was calculated as $7.81 \mathrm{ng} /$ spot using a 10:1 signal-to-noise ratio [18].

3.2.4. Selectivity. The peak purity of LAM was assessed by comparing the spectra of the standard and sample solutions at 3 different levels, namely, peak start (S), peak apex (M), and peak end (E) positions of the spot, that is, $r(\mathrm{~S}, \mathrm{M})$ and $r$ 
TABLE 2: Intra- and interday precisions and accuracy of the proposed HPTLC method for the determination of LAM.

\begin{tabular}{|c|c|c|c|c|}
\hline Frequency of analysis & Concentration taken (ng/spot) & Concentration found $\pm \mathrm{SD}^{*}(\mathrm{ng} / \mathrm{spot})$ & RSD (\%) & $\operatorname{Er}(\%)$ \\
\hline \multirow{3}{*}{ Intraday } & 30 & $29.94 \pm 0.27$ & 0.91 & -0.21 \\
\hline & 150 & $150.05 \pm 1.03$ & 0.68 & 0.03 \\
\hline & 250 & $250.26 \pm 0.59$ & 0.24 & 0.11 \\
\hline \multirow{3}{*}{ Interday } & 30 & $30.06 \pm 0.15$ & 0.50 & 0.19 \\
\hline & 150 & $149.55 \pm 1.15$ & 0.77 & -0.30 \\
\hline & 250 & $250.32 \pm 1.95$ & 0.78 & 0.13 \\
\hline
\end{tabular}

${ }^{*}$ Values are the mean of 5 experiments.

TABLE 3: Statistical evaluation of the results obtained by the proposed and reference methods for the determination of LAM in tablets.

\begin{tabular}{|c|c|c|c|c|c|c|c|c|}
\hline Phormosuticl pronartion & Proposed method & & & Reference method $^{\mathrm{d}}$ & & & & \\
\hline Pnarmaceuticas preparation & Mean $\pm S^{a}$ & RSD\% & $S^{2 \mathrm{~b}}$ & Mean $\pm S^{a}$ & RSD $\%$ & $S^{2 \mathrm{~b}}$ & $t^{\mathrm{c}}$ & $F^{\mathfrak{c}}$ \\
\hline Lamictal 100 tablets & $100.08 \pm 0.82$ & 0.82 & 0.67 & $99.62 \pm 0.74$ & 0.74 & 0.55 & 0.94 & 1.22 \\
\hline Lamictal 50 tablets & $99.58 \pm 0.69$ & 0.70 & 0.47 & $100.14 \pm 0.50$ & 0.50 & 0.25 & 1.47 & 1.88 \\
\hline Lamictal 25 tablets & $99.68 \pm 0.62$ & 0.62 & 0.38 & $99.85 \pm 0.83$ & 0.83 & 0.69 & 1.89 & 1.82 \\
\hline Lamotrigine 100 tablets & $99.80 \pm 0.58$ & 0.58 & 0.34 & $99.85 \pm 0.46$ & 0.46 & 0.21 & 0.13 & 1.62 \\
\hline Lamotrigine 50 tablets & $99.91 \pm 0.74$ & 0.74 & 0.55 & $100.01 \pm 1.15$ & 1.15 & 1.32 & 0.17 & 2.40 \\
\hline Lamotrigine 25 tablets & $99.63 \pm 0.76$ & 0.76 & 0.58 & $99.41 \pm 0.96$ & 0.97 & 0.93 & 0.39 & 1.60 \\
\hline Leptrogine 200 tablets & $99.77 \pm 0.58$ & 0.58 & 0.34 & $99.39 \pm 1.04$ & 1.05 & 1.08 & 0.73 & 3.20 \\
\hline Leptrogine 25 tablets & $99.62 \pm 0.82$ & 0.82 & 0.67 & $99.45 \pm 0.80$ & 0.80 & 0.64 & 0.36 & 1.05 \\
\hline Larogen 100 tablets & $99.52 \pm 1.38$ & 1.39 & 1.90 & $99.76 \pm 0.85$ & 0.85 & 0.73 & 0.34 & 2.60 \\
\hline
\end{tabular}

${ }^{\mathrm{a}}$ Mean $\% \mathrm{R} \pm \mathrm{SD}$ of 5 experiments.

${ }^{\mathrm{b}}$ Variance $\left(S^{2}\right)$.

${ }^{\mathrm{c}}$ The theoretical $t$ and $F$ values, 2.31 and 6.39, respectively at $P=0.05$.

$\mathrm{d}$ [9].

(M, E) were also not less than 0.999 in all cases. In addition, LAM was detected at the same $R_{f}$ value in both solutions.

3.3. Assay of Tablets. A single spot at $R_{f}=0.59 \pm 0.1$ was observed in the chromatogram of the drug samples extracted from 4 different commercially available products including the brand and 3 generic products. There was no interference from the excipients commonly present in the tablet matrix. Results obtained were precise as seen by the low values of RSD\%, and they were also in good agreement with the label claim as seen by the satisfactory \% recoveries. It may therefore be inferred that degradation of the drug has not occurred in the marketed formulations that were analyzed by this method. Results obtained by the proposed method were statistically compared with those of a reference method [9]. The developed assay revealed no significant difference in terms of accuracy ( $t$-test) and precision ( $F$-test) at the $95 \%$ confidence level (Table 3 ). The good performance of the method suggests its suitability for routine stability testing and assay of LAM in tablet form.

3.4. Accelerated Degradation of LAM. The ICH Q1A guidelines provide useful definitions and general comments about forced degradation studies. However, details concerning the scope, timing, and best practice are either general or mainly lacking $[15,19,20]$. Moreover, the information on the basic steps to be followed for the development of stabilityindicating methods is neither provided in other regulatory guidelines nor in pharmacopoeias [19, 20]. Generally, 5-20\% degradation is a common consensus for stress studies because overstressing may result in the complete destruction of the drug or may lead to further degradation of the relevant primary degradants [19]. As a result, the stress conditions were varied and finally adjusted in order to degrade approximately 5-20\% of LAM. A stability-indicating HPLC method for its determination was recently published [11]. In that work, LAM did not undergo significant degradation under photolytic or thermal stress. Thus, attempts in this work were directed towards studying its behavior under modulated experimental stress conditions. The proposed method offers substantial advantages over previously published HPTLC methods since it represents a more sensitive, stabilityindicating assay, where detection was achieved at a more selective wavelength. However, though HPTLC offers a more economic, easily handled substitute to HPLC, the latter technique has a wider scope of applications and is generally more appealing to several laboratories. The chromatogram of the base-degraded sample showed 2 additional peaks besides the analyte's peak (Figure 2), while that of the acid-degraded sample showed 2 extra peaks besides those produced by alkaline hydrolysis (Figure 3 ). In addition, the drug's peak area in the treated samples was less than that of the standard's peak (200 ng/spot) indicating that LAM undergoes partial degradation under both acidic and basic 
TABLE 4: \% Recoveries of LAM and $R_{f}$ values of detected peaks under different stress conditions.

\begin{tabular}{lcc}
\hline Condition & (\%) Recovery & $\begin{array}{c}R_{f} \text { value of } \\
\text { detected peaks }\end{array}$ \\
\hline $\begin{array}{l}\text { Acid hydrolysis } \\
\left(5 \mathrm{~N}, 80^{\circ} \mathrm{C}, 2 \mathrm{~h}\right)\end{array}$ & 85.25 & $0.01,0.02,0.06,0.1$ \\
$\begin{array}{l}\text { Base hydrolysis } \\
\left(2.5 \mathrm{~N}, 80^{\circ} \mathrm{C}, 2 \mathrm{~h}\right)\end{array}$ & 77.84 & $0.01,0.1$ \\
$\begin{array}{l}\text { Neutral hydrolysis } \\
\left(80^{\circ} \mathrm{C}, 72 \mathrm{~h}\right)\end{array}$ & 95.91 & - \\
$\begin{array}{l}\text { Hydrogen peroxide } \\
\left(30 \%, 80^{\circ} \mathrm{C}, 4 \mathrm{~h}\right)\end{array}$ & 87.20 & $0.03,0.5$ \\
$\begin{array}{l}\text { Dry heat } \\
\left(100^{\circ} \mathrm{C}, 72 \mathrm{~h}\right)\end{array}$ & 99.22 & - \\
$\begin{array}{l}\text { Humidity } \\
\left(75 \% \mathrm{RH}, 40^{\circ} \mathrm{C}, 72 \mathrm{~h}\right)\end{array}$ & 99.14 & - \\
$\begin{array}{l}\text { Daylight } \\
(72 \mathrm{~h})\end{array}$ & 99.92 & - \\
\hline
\end{tabular}

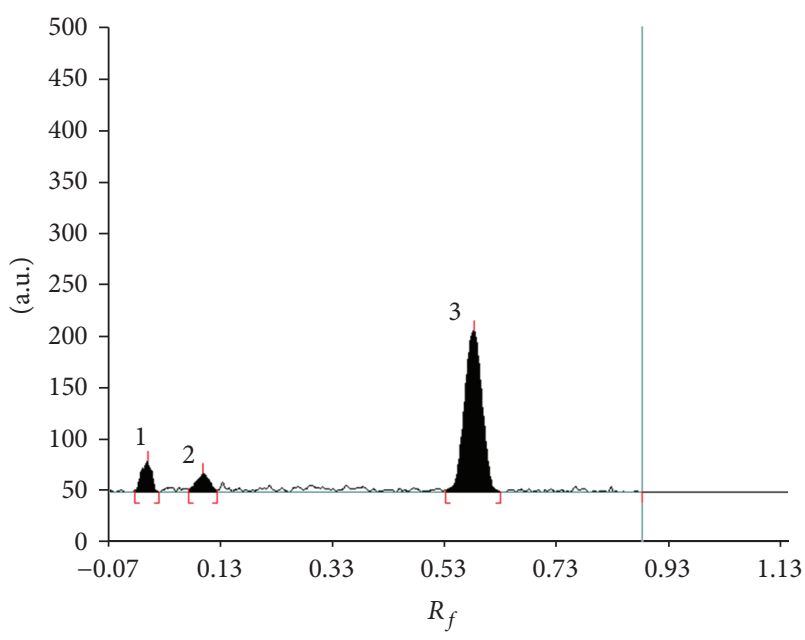

FIGURE 2: HPTLC chromatogram of the base-induced degradation of LAM (200 ng/spot).

conditions. $R_{f}$ values of the detected peaks and \% recoveries of LAM remaining after different degradation processes were calculated and listed in Table 4. According to the results complied in that table, the drug is more susceptible towards hydrolysis in a basic medium than in an acidic one. Oxidative degradation resulted seemingly in the generation of degradation products different from those obtained after acid or alkaline-induced hydrolysis (Figure 4). Other degradation pathways had no significant effect on LAM stability except for neutral hydrolysis which showed a subtle potential. In all forced degradation studies, the purity of the drug's spot was confirmed by the high values of $r(\mathrm{~S}, \mathrm{M})$ and $r(\mathrm{M}, \mathrm{E})$ obtained through the application of the chromatographic peak purity tool.

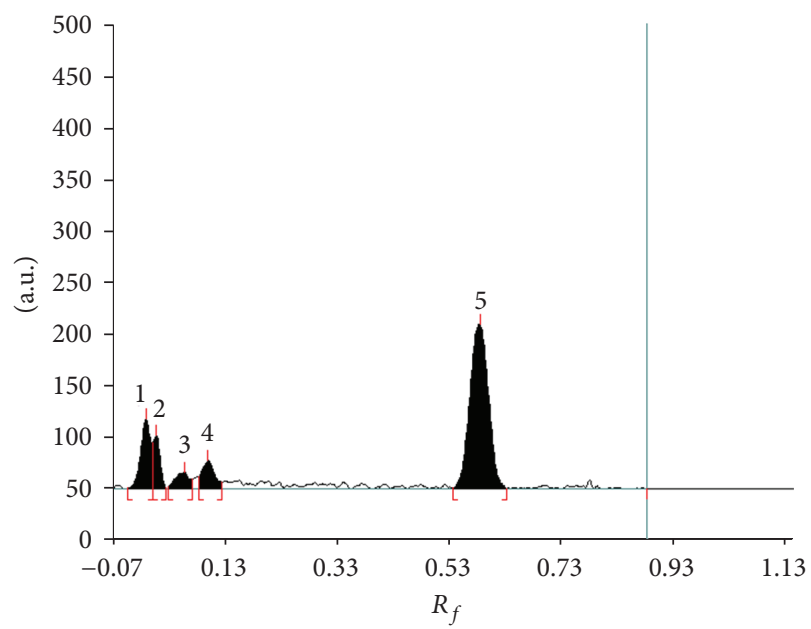

FIGURE 3: HPTLC chromatogram of the acid-induced degradation of LAM (200 ng/spot).

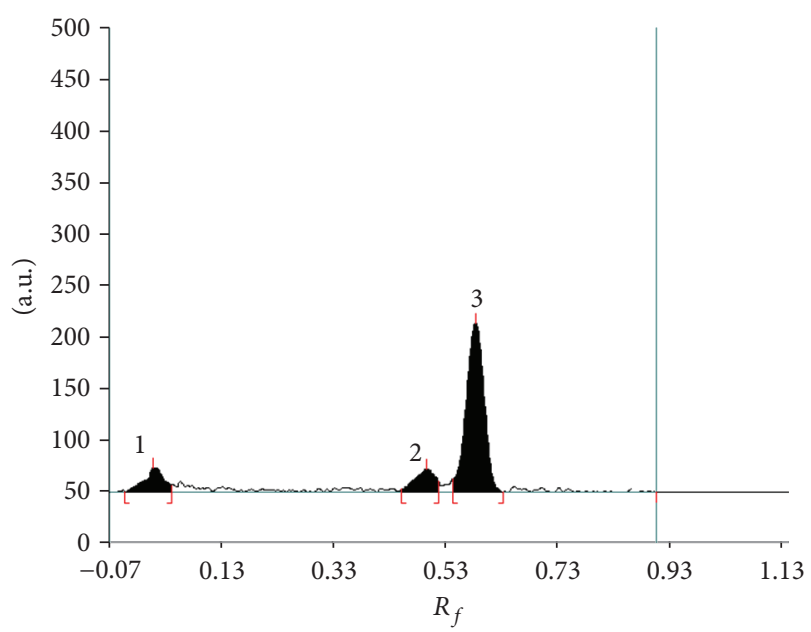

FIGURE 4: HPTLC chromatogram of the hydrogen peroxide-induced degradation of LAM (200 ng/spot).

\section{Conclusion}

According to the ICH guidelines, the safety, quality, and/or efficacy of a drug substance is liable to inadequate storage conditions. Therefore, the need for stability-indicating methods appears indispensable to establish the stability and purity profiles of a drug substance. In this work, LAM was exposed to 7 different stress conditions among which considerable degradation occurred in acidic, basic, and oxidative media. LAM appears more sensitive to alkaline degradation. Whereas heat, humidity, and light had no effect on LAM. The proposed HPTLC method was capable of quantifying low levels of LAM and effectively resolving it from forced degradation impurities. The developed HPTLC assay was also applied to the analysis of tablets, and the ensuing results showed no statistically significance differences from those obtained by a reference method. 


\section{References}

[1] W. O. Foye, Foye's Principles of Medicinal Chemistry, Lippincott Williams \& Wilkins, Philadelphia, Pa, USA, 6th edition, 2007.

[2] C. Dollery, Therapeutic Drugs, Churchill Livingstone, London, UK, 2nd edition, 1999.

[3] S. C. Sweetman, Martindale; The Complete Drug Reference, Pharmaceutical Press, London, UK, 36th edition, 2009.

[4] The United States Pharmacopeia, 34th The National Formulary, 34th Revision, United States Pharmacopeial Convention, Washington, DC, USA, 29th edition, 2010.

[5] The British Pharmacopoeia, Her Majesty's Stationary Office, London, UK, 2010.

[6] J. Emami, N. Ghassami, and F. Ahmadi, "Development and validation of a new HPLC method for determination of lamotrigine and related compounds in tablet formulations," Journal of Pharmaceutical and Biomedical Analysis, vol. 40, no. 4, pp. 999-1005, 2006.

[7] N. F. Youssef and E. A. Taha, "Development and validation of spectrophotometric, TLC and HPLC methods for the determination of lamotrigine in presence of its impurity," Chemical and Pharmaceutical Bulletin, vol. 55, no. 4, pp. 541-545, 2007.

[8] M. C. Sharma and S. Sharma, "Validated densitometric method for the quantification of lamotrigine in dosage form," International Journal of PharmTech Research, vol. 3, no. 2, pp. 1174-1178, 2011.

[9] M. T. Martins, C. S. Paim, and M. Steppe, "LC and UV methods for lamotrigine determination in pharmaceutical formulation," Chromatography Research International, vol. 2011, Article ID 860168, 8 pages, 2011.

[10] N. M. El-Enany, D. T. El-Sherbiny, A. A. Abdelal, and F. F. Belal, "Validated spectrofluorimetric method for the determination of lamotrigine in tablets and human plasma through derivatization with o-phthalaldehyde," Journal of Fluorescence, vol. 20, no. 2, pp. 463-472, 2010.

[11] P. Srinivasulu, K. Mukkanti, B. R. Reguri, and K. S. V. Srinivas, "Development of a validated stability indicating LC method for lamotrigine," Chromatographia, vol. 70, no. 1-2, pp. 271-276, 2009.

[12] S. K. Motwani, R. K. Khar, F. J. Ahmad et al., "Stability indicating high-performance thin-layer chromatographic determination of gatifloxacin as bulk drug and from polymeric nanoparticles," Analytica Chimica Acta, vol. 576, no. 2, pp. 253-260, 2006.

[13] N. Vadera, G. Subramanian, and P. Musmade, "Stabilityindicating HPTLC determination of imatinib mesylate in bulk drug and pharmaceutical dosage form," Journal of Pharmaceutical and Biomedical Analysis, vol. 43, no. 2, pp. 722-726, 2007.

[14] A. Venkatachalam and V. S. Chatterjee, "Stability-indicating high performance thin layer chromatography determination of paroxetine hydrochloride in bulk drug and pharmaceutical formulations," Analytica Chimica Acta, vol. 598, no. 2, pp. 312-317, 2007.

[15] ICH [Stability Testing of New Drug Substances and Products Q1A (R2)], International Conference on Harmonisation, Food and Drug administration, Geneva, Switzerland, 2003.

[16] D. L. Massart, B. G. M. Vandeginste, L. M. C. Buydens, S. De-Jong, P. J. Lewi, and J. Smeyers-Verbeke, Data Handling in Science and Technology, Handbook of Chemometrics and Qualimetrics: Part A, vol. 20, Elsevier Science, Amsterdam, The Netherland, 1997.
[17] V. V. Nalimov, The Application of Mathematical Statistics to Chemical Analysis, Pergamon Press, Oxford, UK, 1963.

[18] ICH [Validation of Analytical Procedures: Methodology (Q2R1)], International Conference on Harmonisation, Food and Drug administration, Geneva, Switzerland, 1996.

[19] K. Huynh-Ba, Handbook of Stability Testing in Pharmaceutical Development: Regulations, Methodologies and Best Practice, Springer Science, Business Media, New York, NY, USA, 2009.

[20] M. Bakshi and S. Singh, "Development of validated stabilityindicating assay methods-critical review," Journal of Pharmaceutical and Biomedical Analysis, vol. 28, no. 6, pp. 1011-1040, 2002. 

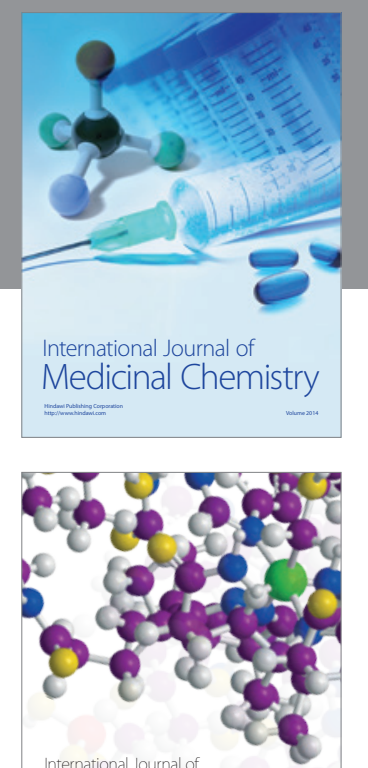

\section{Carbohydrate} Chemistry

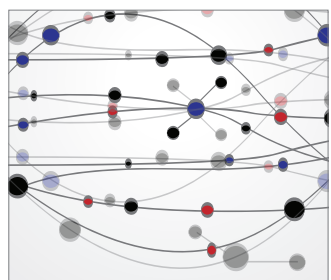

The Scientific World Journal
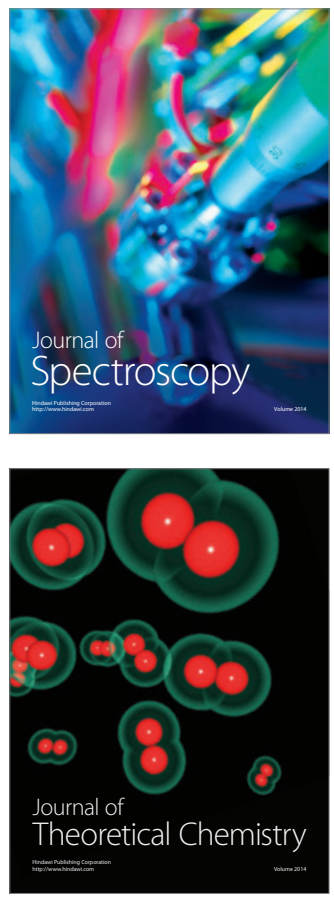
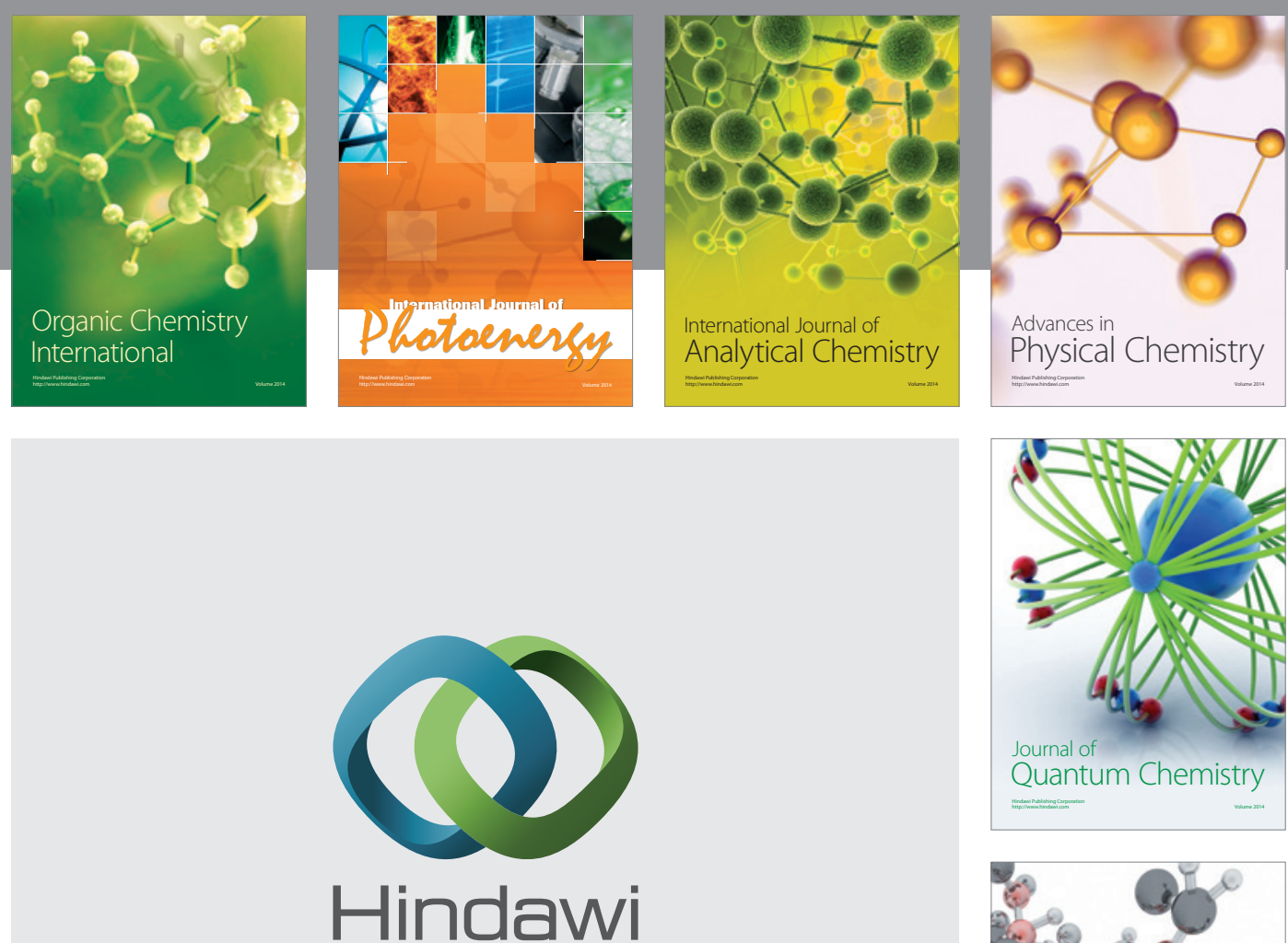

Submit your manuscripts at

http://www.hindawi.com

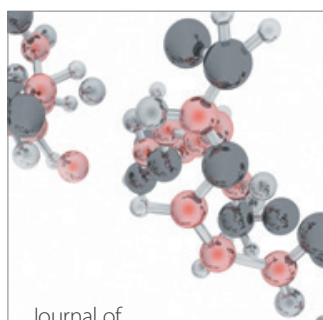

Analytical Methods

in Chemistry

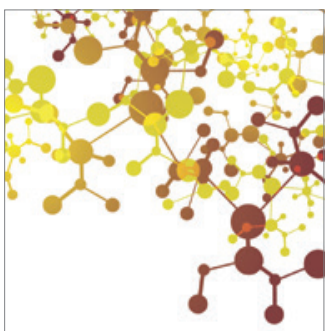

Journal of

Applied Chemistry

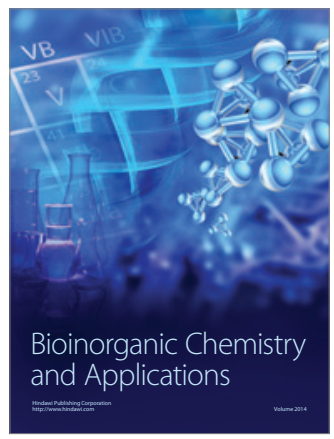

Inorganic Chemistry
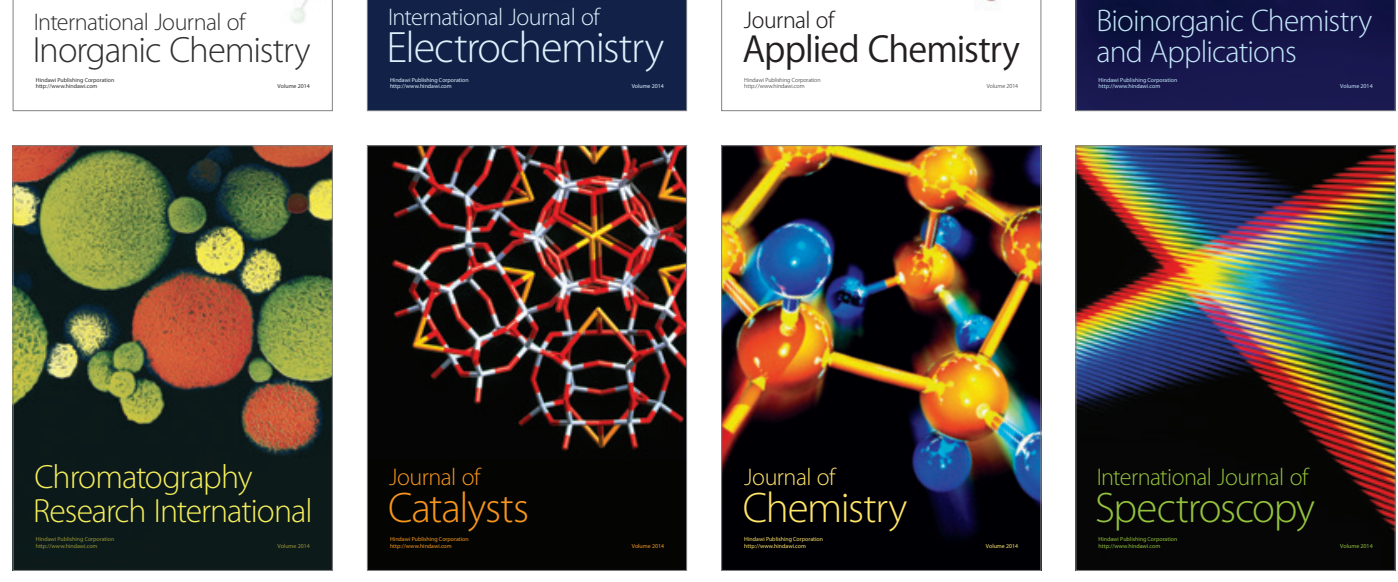